\title{
Inspeção sanitária de produtos de origem animal: o debate sobre qualidade de alimentos no Brasil
}

\section{Sanitary inspection of animal products: discussing food quality in Brazil}

\author{
Michelle Cristine Medeiros Jacob ${ }^{a}$ \\ (iD) https://orcid.org/0000-0002-4881-7285 \\ E-mail: michellejacobळoutlook.com.br \\ Elaine Azevedob \\ (D) https://orcid.org/0000-0002-9637-6III \\ E-mail: elainepeledळgmail.com \\ aniversidade Federal do Rio Grande do Norte. Laboratório Horta \\ Comunitária Nutrir. Natal, RN, Brasil. \\ buniversidade Federal do Espírito Santo. Departamento de \\ Ciências Sociais. Vitória, ES, Brasil.
}

\section{Resumo}

No Rock in Rio de 2017 a Vigilância Sanitária apreendeu, por falta do selo federal de inspeção sanitária, mais de 16 okg de produtos de origem animal, incluindo queijos e linguiças artesanais, de uma renomada chef brasileira. Este evento reacendeu o debate sobre a qualidade dos alimentos no país. Neste artigo, propomos uma discussão sobre a inspeção de produtos animais no Brasil e defendemos um conceito amplo de qualidade, utilizando um método que se baseia na proposta de ensaio de Adorno. Apresentamos o cenário nacional da inspeção, definindo responsabilidades governamentais, conflitos de interesses e propostas em andamento para revisar as normativas específicas vigentes. Em seguida, abordamos a ampliação do conceito de qualidade de alimentos, contextualizando-o no movimento contemporâneo intitulado quality turn. Por fim, apontamos os desafios do cenário político brasileiro e destacamos a necessidade das reformas epistemológica, política e ética para o debate sobre a qualidade de alimentos visando a promover a segurança alimentar e nutricional da população brasileira.

Palavras-chave: Segurança Alimentar e Nutricional; Vigilância Sanitária; Qualidade dos Alimentos; Alimentação Saudável.

\section{Correspondência}


In 2017, at Rock in Rio, Sanitary Surveillance seized more than $160 \mathrm{~kg}$ of animal products, including cheese and hand-crafted sausages, from a renowned Brazilian chef for lack of a federal sanitary inspection stamp. This event rekindled the debate on food quality in the country. In this paper, we discuss animal products' inspection in Brazil and advocate for a broad concept of quality. Our method relays on Adorno's essay proposal. We present the national scenario of the inspection, defining governmental responsibilities, conflicts of interest, and undergoing proposals to review current laws. Then we approach the expansion of the concept of food quality, contextualizing it in the contemporary movement called "quality turn". Lastly, we indicate the challenges of the Brazilian political scenario and highlight the epistemological, political and ethical reforms needed for the debate on food quality to promote the Food and Nutrition Security of the Brazilian population.

Keywords: Food and Nutrition Security; Sanitary Surveillance; Food Quality; Healthy Diet.
Segundo o Decreto n ${ }^{0}$ 9.013/2017 (Brasil, 2017a), que regulamenta a Lei $n^{0} 7.889 / 1989$, para garantir a comercialização de produtos de origem animal em todo território brasileiro é preciso obter um registro ou selo de inspeção, emitido pelo Serviço de Inspeção Federal (SIF).

As normas sanitárias que regem a obtenção do registro SIF estão alinhadas com o Codex Alimentarius, um programa criado pela Organização Mundial da Saúde para estabelecer normas internacionais na área de alimentos e pressionar países membros a adotarem diretrizes de segurança sanitária válidas em escala internacional, mesmo para produtos comercializados localmente (Ribeiro; Jaime; Ventura, 2017). A preocupação de base que subsiste nessas normas é com a segurança alimentar, do inglês food safety, que se refere às condições e práticas que preservam a qualidade sanitária dos alimentos e visa a prevenção de contaminação e doenças de origem alimentar ao longo do sistema alimentar (FAO, 2019).

Pensado e analisado de forma limitada ao longo de décadas, o conceito de segurança alimentar, além de ser incapaz de promover a segurança de sistemas alimentares globais, como demonstram as epidemias e pandemias zoonóticas (ex.: gripe aviária, SARSCoV-2 etc.), institucionalizou as desigualdades no acesso às cadeias produtivas, produzindo vantagens para empresas com melhores condições de investir no ajuste aos padrões internacionais impostos (Gonzalez, 2002; Jones et al., 2013). Ao mesmo tempo, o modelo limita a inclusão produtiva da agricultura familiar, que encontra dificuldades de adequação a esse processo que envolve grande volume de investimento em instalações e equipamentos (Cruz; Schneider, 2010).

O que pauta essa discussão é a ideia de qualidade de alimentos. $\mathrm{O}$ art. 10 do Decreto $\mathrm{n}^{0} 9.013$ define qualidade como "conjunto de parâmetros que permite caracterizar as especificações de um produto de origem animal em relação a um padrão desejável ou definido, quanto aos seus fatores intrínsecos e extrínsecos, higiênico-sanitários e tecnológicos" (Brasil, 2017a). A discussão atual sobre redes agroalimentares alternativas e produtos regionais, 
tradicionais, associados à cultura e local de origem, reposiciona a ideia de qualidade apresentada nesse decreto, migrando de uma perspectiva biologicista e industrial para outra ampliada, pautada na segurança alimentar e nutricional (SAN) (Darolt et al., 2016). A SAN amplia o debate proposto com o conceito de segurança de alimentos ao reconhecer que outros condicionantes sociais, ambientais e econômicos modulam nossa relação com os alimentos e os efeitos que dela advêm. A SAN é definida como um estado no qual as pessoas acessam alimentos adequados, em quantidade e qualidade, sem comprometer outras necessidades básicas, e salvaguardando a diversidade cultural, a sustentabilidade econômica, social e ambiental.

Aqui nos cabe compreender, no contexto do conceito de SAN, a ideia de qualidade. Essa discussão ampliada é de relevo para a área da saúde, visto que produtos artesanais, tradicionais, que têm como base ingredientes locais e com baixo nível de processamento, são importante alternativa à oferta de produtos ultraprocessados. É importante mencionar que, no país, a produção e o consumo de alimentos processados pela grande indústria crescem em paralelo com o avanço da obesidade e das doenças crônicas não transmissíveis relacionadas ao sobrepeso (Canella et al., 2014). Esses riscos devem ser considerados pelos órgãos de inspeção e vigilância sanitária no Brasil, visto o dever do Estado de atuar para reduzir o risco de doenças e de outros agravos, conforme estabelecido na Constituição Federal, nos artigos 196 a 200.

Além disso, conforme já mencionamos, os frequentes surtos causados por alimentos de origem animal (vaca louca, gripe aviária, febre suína africana) não são capazes de promover um debate sobre a insuficiência do sistema de criação animal intensivo em produzir alimentos de qualidade. Essa, sem dúvidas, é uma temática que deveria nos instigar a pensar se a qualidade de alimentos com SAN, no sistema alimentar ocidental globalizado, dependeria da adoção de novas racionalidades alimentares, tais como as diversas formas de dietas baseadas em vegatais. Entretanto, tais questões não são objeto de análise deste ensaio.

Este ensaio propõe uma discussão sobre a inspeção de produtos de origem animal no Brasil e advoga pela adoção do conceito de qualidade alimentar, frequentemente pautado pela perspectiva biologicista e industrial, que desconsidera os aspectos sociais, econômicos, ambientais e, inclusive, nutricionais, da produção e consumo de alimentos.

Como perspectiva de método adotamos a proposta de ensaio de Theodor Adorno (2003). O objetivo de um ensaio para Adorno é explorar, questionar, atacar o objeto como forma de romper com imagens familiares, buscar sentidos, identificar pontos cegos e, por fim, adquirir uma compreensão mais ampla sobre a questão em jogo. Ele denomina essa disposição de explorar o objeto de impulso antissistemático, pois "ataca de diversos lados e reúne no olhar de seu espírito aquilo que vê, pondo em palavras o que o objeto permite vislumbrar sob as condições geradas pelo ato de escrever" (Adorno, 2003, p. 35-36).

Iniciamos o ensaio com uma discussão sobre o caso da inspeção de produtos de origem animal no contexto nacional, definindo responsabilidades nas esferas governamentais, pontos de vistas conflitantes entre os diversos atores do sistema alimentar, e propostas de revisão de legislação em andamento que visam corrigir desigualdades de oportunidades no acesso a este mercado. Na sequência, problematizamos o conceito de qualidade de alimentos, ampliando sua compreensão e contextualizando-o no movimento contemporâneo denominado "virada para a qualidade" (quality turn). Para concluir, localizamos essa reforma epistemológica da qualidade como uma necessidade de reforma ética ampliada na governança de alimentos, dada sua importância como bem vital, social e político.

\section{caso da inspeção de produtos de origem animal no Brasil}

A discussão sobre a dificuldade de acesso de agricultoras(es) familiares, representantes da agroindústria rural de pequeno porte, ao mercado de produtos de origem animal não é nova. Toda história gira em torno da obtenção do registro ou selo de inspeção emitido pelo SIF.

Outros estudos confirmam que a presença do carimbo dos serviços de inspeção alimentar é um atributo que influencia a decisão de compra dos consumidores. Além disso, cresce o interesse pela 
rotulagem e rastreabilidade de alimentos; nesse caso, a rastreabilidade bovina está cada vez mais atrelada à noção de segurança alimentar (Cruz; Schneider, 2010; Lopes et al., 2017; Murdoch, 2003).

Os serviços de inspeção nos estabelecimentos fabricantes de produtos de origem animal (carne, leite, ovos, pescado, mel e seus derivados) no Brasil são de responsabilidade do Ministério da Agricultura, Pecuária e Abastecimento (Mapa) e das Secretarias de Agricultura. ${ }^{1}$ A divisão dos serviços em âmbito nacional pode ser visualizada no Quadro 1 (Brasil, 2017b, 2019).

\section{Quadro I - Divisão dos serviços de inspeção de produtos de origem animal no Brasil}

Serviço de Inspeção Municipal (SIM): realizado pelas Secretarias Municipais de Agricultura. Com esse registro é possível comercializar os produtos apenas no município.

Serviço de Inspeção Estadual (SIE): realizado pelas Secretarias Estaduais da Agricultura. A venda é permitida no âmbito do estado.

Serviço de Inspeção Federal (SIF): realizado pelo Mapa. O SIF autoriza a comercialização em todo território brasileiro.

Fonte: Brasil (2017b, 2019)

Em resumo, um produto que tenha registro sanitário estadual não poderá ser comercializado em outro estado devido à barreira geográfica. Neste caso, fica a pergunta: o que está em pauta é o controle sanitário? Esse caso é ilustrativo do ocorrido no evento Rock in Rio, em 2017, quando a Vigilância Sanitária, responsável pela fiscalização no comércio, apreendeu mais de $160 \mathrm{~kg}$ de produtos, entre queijos e embutidos artesanais, da cozinha da chef Roberta Sudbrack, por falta do registro de inspeção sanitária federal. O queijo possuía o selo de inspeção estadual (SIE) do estado do Pernambuco, significando que o alimento só poderia ser comercializado lá. Todavia, o evento era no Rio de Janeiro. 0 produto não estava impróprio para consumo, ele já havia sido inspecionado. A irregularidade era de comercialização.

Na opinião da Confederação Nacional dos Trabalhadores Rurais Agricultores e Agricultoras Familiares (Contag), ficam dúvidas se o que está em pauta é o controle sanitário de alimentos ou a criação de reserva de mercado para os grandes empreendimentos (Tozzi, 2017). Requerer um SIF é um processo reservado para atores de grande fôlego corporativista. Para obter o registro, o estabelecimento precisa elaborar um projeto de construção/instalação que constitui um processo para aprovação prévia. Uma vez analisado, e caso seja aprovado, este retornará ao demandante para fins de conhecimento e início das obras. Durante o desenrolar da construção o SIF poderá visitar a obra para verificar os trabalhos. Após o término das obras deve ser solicitada uma visita para então ser realizado o Laudo Técnico Sanitário do estabelecimento, o qual também deve ser incluído no processo. Após a obtenção do registro no SIF, autoriza-se seu funcionamento (Brasil, 2019).

As agroindústrias rurais encontram dificuldades de adequação a esse processo que envolve grande volume de investimento em instalações e equipamentos, além de ser demorado e oneroso. A Contag questiona há décadas os limites para a adequação dessas regras e exigências impostas ao agricultor familiar. Acesso a crédito; adequação das plantas e padrões de qualidade SIF para pequenas estruturas de produção; reformulação da legislação existente com o apoio de profissionais e pesquisadores com o fim de adequá-la garantindo a segurança sanitária do alimento; e a formalização da atividade de agricultores familiares e revisão do sistema tributário são algumas de suas reivindicações.

Sobre a dificuldade de acesso a este mercado, o caso dos abatedouros é ilustrativo. aqueles de

1 Além dos produtos de origem animal, cabem ao Mapa a inspeção de vegetais in natura e bebidas (fermentadas, não fermentadas e alcoólicas). À Agência Nacional de Vigilância Sanitária (Anvisa), ligada ao Ministério da Saúde, cabe o controle sanitário da produção e comercialização de farinhas e produtos de origem vegetal processados, tais como doces, conservas, biscoitos e outros. Cabe ainda à Anvisa $(2000,2010)$ a inspeção de demais alimentos processados, com registro obrigatório ou com dispensa de registro, além de aditivos alimentares, conforme RDC nº 27/2010, anexos I e II, e Resolução nº 23/200o, item 5.1.6. 
pequeno porte, hoje, são praticamente inexistentes ou se constituem em projetos fadados ao fracasso, interrompidos antes mesmo de serem finalizados. A sensação é de fazer parte de um romance kafkiano no qual os personagens são culpabilizados por um crime que não compreendem ter cometido; como Josef K., encaram uma sequência de surpresas infindáveis (Kafka, 2005). Os abatedouros de pequenos municípios também não estão imunes, sendo frequentemente fechados. Habitam uma desconcertante distopia, arquitetada por uma lei maior e autorizada pelo paradigma tecnocrático vigente (Vilela, 2017).

No final, as(os) pecuaristas de origem familiar são vencidas(os) pelo cansaço. O resultado é a centralização da compra de carnes em frigoríficos industriais, muitas vezes distantes, para onde também vão os recursos que circulariam localmente. Como exemplo brasileiro, podemos citar a concentração do abate de carne em frigoríficos industriais, com destaque para a Friboi, sob os domínios da JBS S.A., líder de vendas em carne bovina no Brasil (JBS apresenta..., 2019). Cabe aqui uma incômoda informação que pode complexificar ainda mais esse contexto: de acordo com o Portal da Transparência, em 2014, as empresas alimentícias doaram quase 500 milhões de reais a membros do Congresso Nacional, antes de o Supremo Tribunal Federal proibir contribuições de empresas em 2015. O maior doador para candidatos do Congresso foi a JBS, que destinou quase 350 milhões de reais a candidatos. Nos Estados Unidos, entre 2007 e 2014, essa mesma empresa registrou o terceiro maior gasto com atividades de lobby alimentar entre empresas do setor (US\$ 7,15 milhões) (Azevedo, 2019).

Como superar essas restrições, contornar práticas de clientelismo político e favorecer a agroindústria rural de pequeno porte da agricultura familiar estimulando sua inclusão produtiva? Como não inviabilizar o já fragilizado vínculo entre produção animal e agricultura familiar, uma vez que tais alimentos são essenciais para o autoconsumo e a manutenção da lógica de autonomia e policultura de um sistema cada vez mais desqualificado pelas atuais políticas públicas?

Uma das propostas vem da criação do Sistema Unificado de Atenção à Sanidade Agropecuária (Suasa), resultado de décadas de engajamento político da agricultura familiar. Ele permite a comercialização dos produtos de origem animal em todo o território brasileiro pelo princípio da equivalência sanitária, de acordo com o Decreto $n^{0} 5 \cdot 741 / 2006$. Ou seja, se o produto tem integridade sanitária para ser comercializado no município, pode ser comercializado em todo território nacional. O Suasa, portanto, é um sistema unificado e descentralizado de regulamentação. Para garantir o padrão sanitário é que o Sistema Brasileiro de Inspeção de Produtos de Origem Animal (Sisbi-POA), normatizado pela Instrução Normativa (Mapa) $n^{0} 16$ de 2015, faz parte do Suasa, possuindo um selo específico para identificação dos produtos (Brasil, 2017b). A ideia é que o Suasa respeite as especificidades regionais de produtos nas diferentes escalas de produção. Neste cenário, estados e municípios poderão ditar normas específicas para a pequena agroindústria, sem fugir do foco que é a qualidade sanitária. Todavia, a adesão dos municípios e estados é voluntária, o que faz com que ela seja limitada até o momento.

Outra opção inexistente no Brasil e já praticada em outros países são os mobile slaughter units (MSU), ou abatedouros itinerantes, descritos no relatório de apoio ao locavorismo ${ }^{2}$ apresentado ao Congresso estadunidense (Johnson; Aussenberg; Cowan, 2013). Abatedouros itinerantes são equipamentos inspecionados pelas agências estaduais de vigilância sanitária que atendem até os(as) agricultores(as) familiares que desejam vender sua carne e derivados em pequena escala nos mercados locais, mas não têm acesso aos abatedouros mais distantes ou recursos para o transporte de animais. Eles podem atender coletivamente a vários produtores familiares em áreas nas quais os serviços de abate são inviáveis ou indisponíveis. Essa opção não inviabiliza a importância do Suasa, mas permite

\footnotetext{
2 "Movimento alimentar que emergiu nos últimos seis anos e que incorpora as noções de food miles e de alimento local. Food miles é um termo cunhado por Tim Lang no início dos anos 1990 que se refere à distância percorrida pelos alimentos durante seu processo produtivo e seus impactos ambientais. Locavore é a pessoa interessada em comprar e consumir alimentos produzidos localmente” (Azevedo, 2015, p. 81).
} 
o desenvolvimento da agricultura familiar associada ao locavorismo, que também é uma discussão relevante e que merece abordagem aprofundada.

Mais recentemente, a Lei $n^{0} 13.680 / 2018$ foi noticiada como uma legislação pioneira que derruba os limites geográficos no comércio de produtos com inspeção estadual e municipal. Ela dispõe sobre o processo de fiscalização de produtos alimentícios de origem animal produzidos de forma artesanal. Neste caso, desde que submetidos à fiscalização de órgãos de saúde pública dos estados e do Distrito Federal, a comercialização interestadual é permitida. 0 produto artesanal será identificado, em todo o território nacional, por um selo único com a indicação ARTE. Ainda não há consenso sobre o real efeito do selo ARTE, visto que o Sisbi já abrangia o objetivo de conferir equivalência sanitária desde 2011. Contrariando as expectativas positivas em torno do selo ARTE, o Decreto $\mathrm{n}^{0}$ 9.918/2019, que regulamenta a Lei $\mathrm{n}^{0} 13.680 / 2018$, mantém o foco da qualidade em aspectos higiênicosanitários e parece não dimensionar as exigências às dimensões e finalidade do empreendimento. Dado o curto período da vigência da normativa, pontos importantes na análise de seus reais impactos para o(a) agricultor(a) familiar ainda não são claros.

Por fim, outra iniciativa governamental que merece destaque vem da Anvisa. Ainda que esse não seja órgão de competência para inspeção de produtos de origem animal, a Agência vem deesenvolvendo um movimento de aproximação da vigilância sanitária com microempreendedores individuais (MEI), empreendimentos familiares rurais (EFR) e empreendimentos econômicos solidários (EES). Com a Portaria ${ }^{0}$ 523/2017, que institui o Programa para Inclusão Produtiva e Segurança Sanitária (Praissan), a ANVISA busca estender as ações de vigilância sanitária às crescentes relações de consumo que se estabelecem em torno dos produtos e serviços oriundos do microempreendedorismo. Esse movimento governamental é positivo porque indica uma ampliação da compreensão que o estado tem de seu papel em promover a inclusão produtiva. É positivo ainda porque reconhece no texto da normativa que a ampliação do acesso a produtos e serviços oferecidos por esses microempreendedores impacta positivamente na segurança alimentar e nutricional da população brasileira.

\section{A qualidade no contexto da segurança alimentar e nutricional}

Não há dúvidas de que o modelo vigente favorece os grandes complexos produtores tecnificados e estrangula as pequenas agroindústrias rurais (Locatel, 2012). No final, são recompensados aqueles que injustamente produzem alimentos por preços mais baixos, de qualidade nutricional questionável, comprometendo a saúde humana, sem qualquer respeito ao bem-estar dos animais e aos recursos naturais. Além disso, autorizados pelo livre mercado, são sequer responsabilizados por quaisquer uma das diversas externalidades produzidas neste processo (Rocha, 2007). O modelo tecnocrático da decisão, que estimula a participação da indústria e exclui a sociedade civil do processo de tomada de decisão, deve ser substituído pelo modelo democrático por meio do fortalecimento das instâncias de controle social, ação comunitária e participação social (Lang, 2005). Essas vias garantiram todos os avanços conquistados até o momento neste debate: de propostas de revisão de legislação até a criação de formas colaborativas de atuação, como é o caso de consórcios entre municípios para construção de abatedouros. Um dos casos mais exitosos no cenário nacional fica com o queijo canastra produzido com leite cru, hoje certificado pelo Instituto Mineiro de Agropecuária (IMA). Pode-se ainda pensar na importância de estimular as locality foods - ou alimentos com identificação local -, que carregam um sentido de tradição e territorialidade alimentar cada vez mais valorizado no mercado de alimentos.

Neste sentido, o extinto Conselho Nacional de Segurança Alimentar e Nutricional (Consea) produziu uma lista de recomendações relativas ao tema com o fim de pautar a agenda governamental para que sejam adotadas normas sanitárias mais justas, inclusivas e adequadas às dinâmicas de produção, circulação e consumo de alimentos resultados de uma enorme diversidade de saberes e fazeres tradicionais representativos da cultura brasileira (Brasil, 2018). As recomendações, no âmbito da regulação e participação social, produção e abastecimento são dirigidas a Câmara Interministerial de SAN (Caisan), Mapa, Casa Civil, Suasa e Anvisa. De acordo com a exposição de 
motivos, as exigências e entraves sanitários têm impacto direto em programas e políticas públicas voltados para o acesso à alimentação adequada e saudável, tais como o Programa de Aquisição de Alimentos (PAA) e o Programa Nacional de Alimentação Escolar (PNAE), principalmente na aquisição de produtos de origem animal.

Cabe ainda acrescentar que a vantagem dos grandes complexos produtores não se encerra no âmbito dos dispositivos legais, deixando expostas as fragilidades da governança nacional, como bem demonstrou a Operação Carne Fraca no ano de 2017, colocando em discussão a atuação de funcionários do Mapa acusados de corrupção e favorecimento de empresas em troca de valores em dinheiro, colocando em risco a saúde da população (Nunes, 2017).

A apropriação do termo qualidade pela grande indústria o limita a aspectos sanitários, aplicados a alimentos comercializáveis em escala internacional com tempo estendido de vida de prateleira. Tais convenções fortalecem um regime regulatório higiênico-burocrático que permite aos grandes varejistas a manutenção do controle sobre o sistema alimentar (Marsden, 2004).

A proposta de equivalência sanitária busca aumentar o acesso a produtos não apenas seguros do ponto de vista microbiológico; antes, volta-se ao complexo e ambicioso conceito de alimentos saudáveis e adequados ${ }^{3}$ sob as premissas da SAN que preveem alimentos seguros também do ponto de vista da contaminação química e do equilíbrio nutricional, capazes de promover a saúde social e ambiental, conectados com a cultural local e promotores da resiliência econômica das(os) agricultoras(es) familiares.

Diversos autores apontam que vivemos em um momento denominado "virada para a qualidade" (quality turn), associado à proliferação de redes agroalimentares alternativas, que operam à margem dos principais circuitos industriais, em resposta à demandas por alimentos associados à cultura local, ao território e pautados em relações de confiança entre os atores do sistema alimentar (Goodman; Dupuis; Goodman, 2012). Segundo Schneider e Ferrari (2015), esse processo é resultado de consumidores cada vez mais reflexivos e informados, que passam a exigir produtos com qualidade, mais saudáveis e com identificação de procedência.

Assim, para além das propostas práticas oferecidas, cabe espaço para reflexão e ação na janela de oportunidade que se expõe e que se relaciona com a teoria e a prática sobre educação alimentar e nutricional (Brasil, 2012), visando o resgate da alimentação para além de seu aspecto biológico e sanitário, explorando toda sua integração com o sistema alimentar.

Neste ponto, a qualidade transcende os requisitos higiênico-sanitários e tecnológicos e abarca em seu escopo a contaminação química, o equilíbrio nutricional, o frescor, o sabor, a diversidade, capazes de promover a saúde social e ambiental, conectada com a cultural local, promovendo a resiliência econômica de agricultores (as) familiares (Mason; Lang, 2017).

\section{Considerações finais}

O debate sobre a qualidade continua desafiando especialistas das mais diversas áreas que trabalham com alimentos, um bem vital, social e político que sempre oferece novos elementos àqueles que $o$ estudam para repensá-lo. O que apontamos com este ensaio é a necessidade da incorporação da reforma epistemológica do termo, ampliando sua compreensão para além de uma abordagem biologicista, conforme proposto pelo extinto Consea.

O Consea foi extinto por meio da Medida Provisória MP no 870/2019. A população reagiu. 0 ato de resistência popular Banquetaço, no mês de fevereiro de 2019, em diversas cidades brasileiras, demandou do estado o restabelecimento do Consea e de suas funções como instância de participação representativa. O movimento deu origem a um número significativo de emendas à MP, acatadas no relatório da Comissão Especial e aprovadas pelo Congresso Nacional. Contrariando o trâmite democrático, o restabelecimento do Consea foi vetado pelo presidente da República Jair Messias Bolsonaro

3 De acordo com a Política Nacional de Alimentação e Nutrição (PNAN), entende-se por alimentação adequada e saudável a prática alimentar apropriada aos aspectos biológicos e socioculturais dos indivíduos, bem como ao uso sustentável do meio ambiente (Brasil, 2013). 
no ato de sanção. Ao advogar pelo cumprimento do contrato social, o Consea questionou a lógica do regime alimentar neoliberal, colocando em pauta a necessária reforma política. Sua extinção tem objetivos claros: ela golpeia a participação social e fragiliza a proposta de construção coletiva de políticas que visem fortalecer a SAN.

A reforma epistemológica da noção de qualidade só atinge seu objetivo quando traz consigo esta segunda reforma: a política. A reforma política envolve a repactuação da agenda governamental para que sejam adotadas normas sanitárias mais justas, inclusivas e adequadas às dinâmicas de produção, circulação e consumo de alimentos resultados da diversidade de saberes e fazeres tradicionais que expressam a cultura brasileira. A extinção do Consea se constitui em um verdadeiro obstáculos à prossecução desta reforma.

A natureza vital dos alimentos traz à tona a necessidade de uma terceira reforma, a ética. O debate ético, pautado na busca das motivações que colocam o sistema alimentar em movimento, abre caminho para questionarmos a validade de um contrato social que negocia com a fome em meio ao desperdício, com o sofrimento animal em massa e com a destruição deliberada da vida na Terra. A reflexão ética na governança de sistemas alimentares deve guiar reforma política, para que o Estado cumpra seu papel como regulador de interesses sociais e não aja como um representante de interesses privados. Qualidade: qual e para quem? Perguntas como essa, aliadas à pujante ação social, podem pavimentar nosso caminho em direção a um sistema alimentar justo, que respeite as pessoas, todas as formas de vida e o planeta.

\section{Referências}

ADORNO, T. O ensaio como forma. In: ADORNO, T. Notas de literatura. São Paulo: Editora 34, 2003. p.15-45.

ANVISA - AGÊNCIA NACIONAL DE VIGILÂNCIA SANITÁRIA. Resolução n ${ }^{0}$ 23, de 15 de março de 2000. Diário Oficial da União, Brasília, DF, 16 mar. 2000.

ANVISA - AGÊNCIA NACIONAL DE VIGILÂNCIA SANITÁRIA. Resolução-RDC n² 27, de 6 de agosto de 2010. Diário Oficial da União, Brasília, DF, 9 ago. 2010.
AZEVEDO, E. O ativismo alimentar na perspectiva do locavorismo. Ambiente \& Sociedade, São Paulo, v. 18, n. 3, p. 81-98, 2015.

AZEVEDO, E. Lobbies alimentares. Revista Ingesta, São Paulo, v. 1, n. 1, p. 53-67, 2019.

BRASIL. Ministério do Desenvolvimento Social e Combate à Fome. Marco de educação alimentare nutricional para políticas públicas. Brasília, DF, 2012.

BRASIL. Ministério da Saúde. Secretaria de Atenção à Saúde. Departamento de Atenção Básica. Política Nacional de Alimentação e Nutrição. Brasília, DF, 2013.

BRASIL. Decreto nº 9.013, de 29 de março 2017. Diário Oficial da União, Brasília, DF, 30 mar. 2017a.p. 3 .

BRASIL. Ministério da Agricultura, Pecuária e Abastecimento. Sistema brasileiro de inspeção de produtos de origem animal - Sisbi-POA. Brasília, DF, 2017b. Disponível em:

<https://bit.ly/38HLlCN >. Acesso em: 23 maio 2019.

BRASIL. Conselho Nacional de Segurança Alimentar e Nutricional. Exposição de Motivos 3: regulação sanitária para inclusão produtiva na perspectiva da soberania e segurança alimentar e nutricional. Brasília, DF, 2018. Disponível em: <https://bit.ly/3oBPWlf>. Acesso em: 6 jul. 2020.

BRASIL. Ministério da Agricultura, Pecuária e Abastecimento. Registro de estabelecimentos - SIF ou ER. Brasília, DF, 2019. Disponível em: <https://bit.ly/2YDwTpo>. Acesso em: 23 maio 2019.

CANELLA, D. et al. Ultra-processed food products and obesity in Brazilian households (2008-2009). Plos One, São Francisco, v. 9, n. 3, 2014.

CRUZ, F.; SCHNEIDER, S. Qualidade dos alimentos, escalas de produção e valorização de produtos tradicionais. Revista Brasileira de Agroecologia, [s. l.], v. 5, n. 2, p. 22-38, 2010.

DAROLT, M. et al. Redes alimentares alternativas e novas relações produção-consumo na França e no Brasil. Ambiente \& Sociedade, São Paulo, v. 19, n. 2, p. 1-22, 2016.

FAO - FOOD AND AGRICULTURE ORGANIZATION OF THE UNITED NATIONS. The future of food safety. Roma, 2019.

GONZALES, C. Institutionalizing inequality: the WTO Agreement on Agriculture, Food Security, 
and Developing Countries. Columbia Journal of Environmental Law, Nova York, v. 27, n. 2, p. 433-489, 2002.

GOODMAN, D.; DUPUIS, E.; GOODMAN, M. Alternative food networks: knowledge, practice, and politics. Londres: Routledge, 2012.

JBS APRESENTA portfólio de alto valor agregado na maior feira de alimentos do mundo. JBS, São Paulo, 15 fev. 2019. Disponível em: <https://bit.ly/2ErBxiK>. Acesso em: 23 maio 2019.

JOHNSON, R.; AUSSENBERG, R.; COWAN, T. The role of local food systems in U.S. farm policy. Washington, DC: FAS, 2013. Disponível em: <https://bit.ly/3mZmvVz>. Acesso em: 6 jul. 2020.

JONES, B. et al. Zoonosis emergence linked to agricultural intensification and environmental change. Proceedings of the National Academy of Sciences of the United States of America, Washington, DC, v. 110, n. 21, p. 8399-8404, 2013.

KAFKA, F. O processo. São Paulo: Companhia de Bolso, 2005.

LANG, T. Food control or food democracy? Re-engaging nutrition with society and the environment. Public Health Nutrition, Oxford, v. 8, n. 6A, p. 730-737, 2005.

LOCATEL, C. Tecnificação dos territórios rurais no Brasil: políticas públicas e pobreza. Scripta Nova, Barcelona, v. 16, n. 418, p. 741-798, 2012.

LOPES, M. et al. Fatores associados à percepção e atitude de consumidores de carne bovina com certificação de origem em Uberlândia, Minas Gerais. Revista Ceres, Viçosa, v. 64, n. 1, p. 31-39, 2017.

MARSDEN, T. Theorising food quality: some issues in understanding its competitive production and regulation. In: HARVEY, M.; MCMEEKIN, M.; WARDE, A. (Ed.). Qualities of food. Manchester: Manchester University Press, 2004. p. 129-153.

MASON, P.; LANG, T. Sustainable diets: how ecological nutrition can transform consumption and the food system. Nova York: Routledge, 2017.

MURDOCH, J. The quality 'turn' and alternative food practices: reflections and agenda. Journal of Rural Studies, Amsterdã, v. 19, n. 1, p. 1-7, 2003.

NUNES, V. Veja a lista dos envolvidos na Operação Carne Fraca. Correio Braziliense, Brasília, DF, 17 mar. 2017. Disponível em: <https://bit.ly/2VWU7cU>. Acesso em: 23 maio 2019.

RIBEIRO, H.; JAIME, P.; VENTURA, D. Alimentação e sustentabilidade. Estudos Avançados, São Paulo, v. 31, n. 89, p. 185-198, 2017.

ROCHA, C. Food insecurity as market failure: a contribution from economics. Journal of Hunger \& Environmental Nutrition, Abingdon, v. 1, n. 4, p. 5-22, 2007.

SCHNEIDER, S.; FERRARI, D. Cadeias curtas, cooperação e produtos de qualidade na agricultura familiar: o processo de relocalização da produção agroalimentar em Santa Catarina. Organizações Rurais \& Agroindustriais, Lavras, v. 17, n. 1, p. 56-71, 2015.

TOZZI, V. Legislação sanitária para produtos de origem animal dificulta comercialização da agricultura familiar e ganha visibilidade no Rock in Rio. Contag, Rio de Janeiro, 20 set. 2017. Disponível em: <https://bit.ly/2Z1HD3l>.

Acesso em: 23 maio 2019.

VILELA, S. Perspectivas para a agricultura familiar brasileira: elementos de um projeto político de desenvolvimento rural, para além de uma "questão tecnológica". In: DELGADO, G.; BERGAMASCO, S. (Ed.). Agricultura familiar brasileira: desafios e perspectivas de futuro. Brasília, DF: Ministério do Desenvolvimento Agrário, 2017. p. 244-262.

\section{Agradecimentos}

Agradecemos a E. Jacob, R. Freitas, C. Belarmino, R. Cintrão, C. Dória, C. Oliveira e T. Gurgel pela leitura prévia, comentários e sugestões. Somos gratas também pelos comentários adicionais gentilmente fornecidos por revisores(as) anônimos(as).

\section{Contribuição das autoras}

Jacob concebeu o manuscrito, elaborou o rascunho original e redigiu a versão final. Azevedo colaborou com a revisão e redação final do manuscrito.

Recebido: $23 / 04 / 2020$

Aprovado: $25 / 06 / 2020$ 